\title{
Construction of E-Commerce Credit System Based on Big Data Analysis
}

\author{
Ganglong $\mathrm{Fan}^{1,2}$, Hongsheng $\mathrm{Xu}^{1,2} \mathrm{a}^{*}$ and $\mathrm{Ke} \mathrm{Li}^{1,2}$ \\ ${ }^{1}$ Luoyang Normal University, Luoyang, 471934, China \\ ${ }^{2}$ Henan key Laboratory for Big Data Processing \& Analytics of Electronic Commerce, Luoyang, 471934, \\ China \\ a85660190@qq.com
}

Keywords: Credit system; Electronic commerce;Big data; Electronic signature; Credit information

\begin{abstract}
Credit system is a reflection and evaluation system of comprehensive trust between organizations and individuals. E-commerce as a virtual economy, non contact economy, if there is no perfect credit system as a guarantee, its survival and development will be very difficult. This paper focuses on the analysis of the big data processing technology to build e-commerce credit system model. The paper presents novel model of e-commerce credit system based on big data analysis. The information flow, capital flow and even logistics of electronic commerce form a whole by echoing each other with electronic signatures.
\end{abstract}

\section{Introduction}

In China the fastest developing areas on the one hand, the electronic commerce credit system itself is the existence and development of the best soil, based on the e-commerce and it is easy to establish the credit system of e-commerce, information flow, capital flow and logistics through electronic signature each other to form a whole, in the whole, as long as a little integration analysis, technical processing, can establish a credit system, the credit system is controllable, the electronic commerce interaction.

The e-commerce has many potential tax risk of direct and indirect taxes. For example, the accident may receive a tax on Internet servers in a region for operational reasons. Electronic business leaders should keep abreast of relevant tax law to date, and to ensure that in making strategic and operational decisions must consider the tax factor; safety for the traditional crime of fraud theft from paper world transferred to the electronic world [1]. The Internet crime year is by year growth trend. In order to deal with this situation, the enterprise must set up an effective security program and regular invasion tests to ensure the effect of electronic commerce elasticity.

At present, big data not only refers to the amount of data is huge, it is more important for the big data analysis, only through analysis to get more intelligent, thorough, valuable information. The data have strategic significance, can effectively enhance the competitive ability, how to grasp in a huge amount of data, but in the have the ability to contain these insights and value of data processing and application.

The effective use of credit information can make all the main market credit information can be connected and cover the whole society, so that those who only engaged in one-off game market entities will no longer have to survive. "Shot for a place" strategy will fail, every transaction subject are forced to repeat the game [2]. But in repeated game, honesty is clearly the optimal strategy.

Electronic commerce credit crisis is increasingly highlighted, false trading, counterfeit behavior, contract fraud, online auction bidding up, infringe upon the legitimate rights and interests of consumers and other illegal acts occur, these phenomena largely restricts our country electronic commerce rapid and healthy development of electronic commerce in our country is short of development the time, electronic commerce and related laws and regulations and management system is not perfect, the lack of credit system, which is the most fundamental reason. To speed up the construction of electronic commerce credit system has become the inevitable choice of economic and social development.

For e-commerce, the rule of law is very important, a new form of trade, must have a re combination of interest distribution, all participants must be within the scope of the law, follow the rules of the game lags behind the fair. China's e-commerce legislation, the law can not meet the needs of the existing electronic 
commerce law is not perfect. It is easy for some consumers, drilling legal loopholes, so dishonesty consumers have increased.

Network security has become a great concern to all walks of life before the problem of network security can not be overlooked, security risks may restrict development of e-commerce, online payment and other transactional applications. It can be said that in the e-commerce development trend of globalization, e-commerce transactions of the credit crisis has quietly hit, false trading, counterfeit behavior, contract fraud. The online auction bidding up, infringe upon the legitimate rights and interests of consumers and other illegal acts occur, these phenomena largely restricts China's e-commerce and global electronic commerce rapid and healthy development.

\section{Analysis of e-commerce credit system}

Security model is based on the site or business enterprise for the parties to the transaction to provide security for the characteristics, to solve the problem of credit risk through this guarantee. The greatest advantage of this model is that the two sides through online transactions reduce the credit risk, but the invisible but aggravated the website or website operator's responsibility [3]. This model is generally applicable to with a specific organization of the industry.

E-commerce represents the future development of trade, its application and promotion will bring more trade opportunities for the members. "In order to promote the rapid development of electronic commerce in China's health, the Ministry of Commerce China established the division of information, the government is mainly responsible for macro planning and guidance for the development of electronic commerce, in order to further promote the application of electronic business in China and the popularization, improve efficiency, reduce costs, expand the market.

Perfect credit management system includes national legislation, on the aspect of credit law enforcement; the government supervision of the credit industry; industry self-discipline and so on. At present, it is still insufficient, did not establish a sound credit management system, lack of effective supervision and punishment mechanism of dishonesty, illegal behavior, as is shown by equation (1).

$$
q(n)=\frac{\gamma^{-1} R^{-1}(n-1) x(n)}{1+\gamma^{-1} x^{H}(n) R^{-1}(n-1) x(n)}
$$

Honesty is the life, is the basic requirement of e-commerce transactions and credit, credit is a kind of wealth, is an irreplaceable competitive. Maybe cheat, fraud can bring short-term benefits, but with the passage of time, it will lose the trust of the people, faith in society, are also unable to obtain long-term, stable cultivation of interests [4]. The credit consciousness of the whole society, should start from the cultivation of people's credit consumption habits, so that more users to accept electronic credit means of payment, accumulated a good credit record, to provide convenience for the day after the consumer credit. All enterprises involved in electronic transactions, to gradually form the self-discipline of the industry norms and standards of social credit business. Awareness, will greatly promote the construction of electronic commerce credit system in the process.

Electronic commerce as a commercial activity, credit is also the basis for the existence and development of the electronic commerce and credit services are developing rapidly emerging field, market prospects, from the relationship between the two, on the one hand, e-commerce needs the credit system and credit system is also likely to be first in the field of electronic commerce has widely used and reflected its value [5]. Because the strongest demand of Electronic Commerce on the credit system, no electronic commerce high risk credit system support; and based on the e-commerce and it is easy to establish a credit system, the flow of information in electronic commerce, capital flow, logistics and electronic signature four mutually cross formation a whole.

Intermediary mode electronic commerce website as a trading intermediary, to participate in the whole process of neutral transactions, such as the "China commodity trading center" requires the deal agreement after the purchase of the party to the payment, the sales side to the goods were to pay the agency in all over the 
network to station when the work of the organization's website, check after the payment and delivery of goods to each other. Obviously, this credit model is to the whole process control of transactions through the management agency website, to ensure that both parties can fulfill their obligations according to the provisions of the contract.

Look at the international level information level in China is very low, the corresponding legislation is lagging behind, and resulting in domestic is in the passive position in the global e-commerce competition. Furthermore, little not trade disputes, and e-commerce disputes in international trade is unique, because the trade between different legal systems. If there is not a mature, unified legal system, trade disputes is not resolved; the current international legal system on electronic commerce is still not complete [6]. The law of our country can not fully meet the needs of the development of information society, as is shown by equation (2).

$$
\left(P^{(\chi)}(1 \mid 1)\right)^{-1}=\left(P^{(\chi)}(1 \mid 0)\right)^{-1}+\Psi^{T}(1) \bar{R}^{-1}(1) \Psi(1)
$$

The main difference is between Internet and the traditional way of communication in its interactive. The Internet is interactive information flow, so that the credit mechanism built this mode of communication is bound to have timeliness and highly dynamic.

A major obstacle to the success of the e-commerce is the lack of consumer confidence in the safety and privacy. Get on the website of independent license sealing helps to manage the uncertainty. There are now many companies can provide such license seal; relationship with advertisers. It is with website more mature, Internet advertising an important in ensuring the right customers access to the correct site becomes more and more.

From the original collection of credit information, to screening, screening, matching, verification, processing, preservation of the formation of "credit data", and then the subsequent data update and maintenance, this process is a closely linked, indivisible. If we only are study the original data collection. Not only will make research lack of coherence, practical significance will also limit the whole study. One of the system constructions of the task is to design credit information sharing mechanism, the credit rating agencies, enterprises, government in some way into the fast access, analysis of the easy access to credit information and complete the custom query, statistics, decision management service and public service functions.

\section{Construction of e-commerce credit system based on big data analysis}

Big data are those that exceed the traditional database system processing capacity data. Its data transfer speed and size requirements are very high, or the structure is not suitable for the original database system. In order to obtain the value of big data, we must choose another way to deal with it. For the business organization, the value of big data is reflected in two aspects: analysis and development two times. For large data analysis can reveal the hidden information. Even in the garage of the venture company also can lower the price to rent the cloud Business Hours.

The goods under the net purchase online, it is now very fashionable and popular e-commerce consumption patterns. However, investigation shows that more than $50 \%$ of the respondents have experienced online shopping information and net real goods do not conform to the situation. Once the customer found the goods have quality problems, not the dealer network or not willing to provide effective customer service to help solve the quality problem of the goods, the customer service as a commitment to attract the consumers focus on the Internet.

Through the network of social phenomena whirling is not difficult to find that lack of credibility is driven by economic interests. China's economy is still underdeveloped, some people in front of the money is very easy to lose their senses, they tend to more profit and take various improper means, it is because of this kind of economic interests and business profits, make people despise the moral and legal way in the network and the "free time". Some website operators can not put long-term vision, just focus on short-term benefits, with the "walk" mentality of business website, after get some benefits disappear, causing the user does not trust in e-commerce [7]. In addition, when in the same on the market, some criminals obtain improper benefits after 
not be punished, there will be a lot of people envy, and then follow the trend, make the e-commerce credit more Defect.

The application of data broadly divided into the following steps: A. data acquisition, verification and filtering; B. classification and stored in the data warehouse; C. data mining is to find association rules and data of the data between the D. data model and parameter establishment; adjustment; e. application development and data based decision support.

A survey on public projects encountered problems of e-commerce report of China's e-commerce credit situation a survey by Chinese Electronic Commerce Association Credit Evaluation Center and the Beijing Normal University Electronic Commerce Research Center survey shows: $<>$ in $1.71 .1 \%$ of the respondents had some of the site's authenticity and legitimacy of the produce $2.62 .1 \%$ doubt; respondents claimed that their personal information has been online business or website abuse; $3.40 .9 \%$ of the respondents in the use of the network or online transactions have had their personal information being stolen.

Although big data currently in the country is still in the initial stage, but the commercial value has been revealed [8]. The future data may become the biggest trading commodities. But the large amount of data and can not be regarded as the characteristics of big data, big data is a large amount of data, data types, the maximum non standardized data value.

In order to avoid fraud phenomenon in e-commerce transactions, must assess and rank the electronic commerce credit, to rank high praise, the lower level of punishment. That is the problem into the credit of enterprises and the electronic commerce credit rating.

Chinese e-commerce environment has been greatly improved, but compared with the credit system in recent more than 200 years in Europe and the United States, Chinese still lacks mature credit system to support the development of electronic commerce [9]. The concern of e-commerce mainly focused on the following aspects: first, the product its shape can not see the body, difficult to identify the pros and cons. Second online payment, and it is transfer of property and risky. Third, it is the dissemination of information on network, easy to be stolen.

\section{The role of credit system in the implementation of e-commerce}

The electronic commerce credit risk is due to virtualization and particularity of network transactions, the main credit information opaque, not exactly caused. Before the transaction, the credit status of the parties to the transaction is difficult to determine, the trading platform of responsibility and rights are not clear, the network in the trading fraud will be impossible to guard against.

Our country has formed the integrity of the company to carry out different types of competition in the market in accordance with the principle of commercial pattern; there are China to assess the integrity of the securities company [10]. However, with the support of the regulatory system is relatively backward. The lack of credit institutions and it is the management of credit activities effectively. There are some credit institutions to take low prices, high rebate, high rating means to snatch the market, make the rating results become a commodity to be bought and sold are not standardized.

E-commerce as a new business model, every transaction activities of it are related to various participants, including the parties involved in the transaction, the electronic commerce website, the third party Logistics Company, bank, tax bureau, industry and commerce, public security and other agencies, each participant will bear the responsibility for the credit they need. Trading in a perfect credit environment, a participant in this environment is not but the construction of e-commerce activities has a sense of integrity will be able to solve the problem and the mechanism of the integrity of the environment need long-term efforts to create social parties. Therefore, we should draw lessons from the relevant legislation in the developed country.

\section{Summary}

The paper presents construction of e-commerce credit system based on big data analysis. Inclusive growth of e-commerce is in the era of big data. Electronic commerce as a virtual economy, non contact economy, honesty is the foundation of the establishment and operation of the system to regulate, but also an important 
condition to prevent e-commerce operation risk effectively. At present, the electronic data interchange and the Internet as the basis, to support the integrity of the international credit system throughout the global integration of the market economy.

\section{Acknowledgements}

This paper is supported by Henan key Laboratory for Big Data Processing \& Analytics of Electronic Commerce, and also supported by the science and technology research major project of Henan province Education Department (17B520026).

\section{References}

[1] [1] Zhang Jingwei, e-commerce credit mechanism construction, logistics science and technology, $2007,(03): 77$.

[2] [2] Hongsheng Xu, Ruiling Zhang. Novel Approach of Semantic Annotation by Fuzzy Ontology based on Variable Precision Rough Set and Concept Lattice, International Journal of Hybrid Information Technology Vol.9, No.4 (2016), pp. 25-40.

[3] [3] Liao Junfeng, Chen Liping, credit problems in electronic payment and their social roots, academic research.2007 (11):79.

[4] [4] Lei Bing. Design and development of e-commerce credit evaluation system. microcomputer information, 2007 (7-3).173-175.

[5] [5] H.-s. XU, R.-1. ZHANG, "Semantic Annotation of Ontology by Using Rough Concept Lattice Isomorphic Model", International Journal of Hybrid Information Technology, Vol.8, No.2, 2015, pp.93-108.

[6] [6] Wang Li, the construction of credit system in electronic commerce, Journal of Jiangsu Polytechnic University, 2013 (6):49.

[7] [7] Bi Qiang, Qi Zhi, baegunbong. Electronic commerce credit information service model of it. information science, 2007 (11).1634-1639.

[8] [8] Wang Jingyi. Credit management of information and e-commerce platform. Science and technology management research.2007 (11):232.

[9] [9] Tao Xuejiao, Hu Xiaofeng, Liu Yang. Big data research, Journal of system simulation, 2013,25S:142-146.

[10] [10] Al Guangxi. Look into the electronic commerce safety countermeasures. Excellent in.2007 (5):8. 